\title{
Comparative study of industrial design undergraduate education in China and USA
}

\author{
Xuefei Huang $^{1}$ (D) Roger Ball $^{2} \cdot$ Wei Wang $^{2}$
}

Accepted: 20 January 2020 / Published online: 25 January 2020

(c) The Author(s) 2020

\begin{abstract}
Industrial design (ID) undergraduate education in China is seen as a new rapidly growing discipline over the past 40 years. China's ID education is not well known in the West due to several barriers: language, the Great Firewall of China which blocks out most of the Western websites and a 12-h time difference. All Chinese ID curriculum and program information are available in Mandarin. The Ministry of Education administers all Chinese design education as well as ID scholarships and faculty exchange grants and its website and documents require translation. The Great Firewall of China blocks 90\% of Western websites including Google making it difficult for Western Scholars to access accurate information about the size and shape of the Chinese ID education landscape. China has a historical relationship between the ID schools in China and the United States. Chinese students are studying or alumni of every American ID program. China and USA share similar program types, dual-track admissions for art and design streams, and academic calendars. In this paper, a model was developed to clarify the features of ID undergraduate education in China and USA, and a survey of eight ID schools was processed. Four aspects were comparatively discussed: (1) types of ID education, (2) ranking, evaluation, and certification of ID schools and programs, (3) curriculum, credits, course features, and yearly schedules of schools, (4) influences coming from the culture and globalization process. Based on the analysis, the similarities and differences in ID undergraduate education between the two countries are discussed. Results show the dual-track modes in China and USA are different. It is mainly reflected in the management and enrollment, curriculum organization, and cultural environment. Implications for the localization, openness, and globalization to ID education are finally discussed together with several directions for future development. The findings are valuable to USA and Chinese ID departments and faculty, researchers, staff and visiting scholars. It is also useful for university administrative units such as registrars, admissions, international offices and exchanges to understand each other.
\end{abstract}

Keywords ID · Industrial design education · Comparative study · Ranking · Certification · Curriculum $\cdot$ Academic calendar $\cdot$ Art $\cdot$ Design $\cdot$ China $\cdot$ USA

Xuefei Huang

huangxuefei@whut.edu.cn

Extended author information available on the last page of the article 


\section{Introduction and background}

100 years ago, the Bauhaus School in Germany had been established to develop a modern industrial design (ID) in higher education. Later, their ideas in design education were inherited in many colleges and universities in Europe and USA, which helped it build a relatively mature education system. By quantitative research of data for more than 20 years, Ilhan (2017) finds that the absolute and relative numbers of undergraduate design students are growing and the leading edge of growth was at private universities and colleges. University's research and application differentiation are bringing uncertainty to design education. Design talents are facing two different career choices: large corporate departments or consultancies. The instruction way, the education concept, and the evaluation type of design discipline need to adapt to change (Kolko 2012). Design activities are influenced by cognitive activities, such as the design process, the designers, and the artifact, bring the difference to the design, which is changing the design result and bringing new demands for design education (Visser 2009).

In the other world, emerging economies like BRICS (Brazil, Russia, India, China, and South Africa) significantly grow their original design quality in recent years with international recognition. With the influence of the western education system in the last decades, the development of ID disciplines in emerging economies took a different pathway with their great industrialization. It has been benefited from and benefited from the socioeconomical development based on its government-driven industrial policy and the unique higher education system. For example, the Chinese Economic Miracle in the past 40 years has driven explosive growth in the Chinese consumer product to the global market. Their designers from their design education system are creating more and more everyday products impact people worldwide. Meanwhile, Chinese consumers with their design taste are consuming more and more products from everywhere. China now the second-largest consumer market will soon be the largest single market place in the world. Today Chinese consumers demand high-quality product design (PD), interactive services and smart systems. Designing for the international market created a massive demand for talented designers. China had been steadily developing its industrial design discipline. Shenzhen, Beijing, Shanghai, and Wuhan, have all been "The World Design Capital, WDC" by World Design Organization in recent years. At the same time, Chinese universities started to build ID majors. According to the statistics of website CHESICC (2019a, b), by 2017, there were 783 ID or PD undergraduate programs, which were hosted by 561 higher education institutions. From the lense of historical review and comparative study, this paper focus on the relationship, the development, and their current industrial design undergraduate education system in China and USA in the context of international design education shifting.

\section{Status of ID education research}

Buchanan (1992) considers that ID needs to integrate designers, manufacturers, and people in the context of symbols, behavior, and ideas. Friedman (2012) believes that design needs to adapt to the changes in social and economic environments, and education needs to respond in skills and knowledge. The meaning of ID is extending to service design, interaction design and experience design, but we still need industrial designers with classic training. The need for masterly use of styles, forms, and materials will never go away (Norman 2010; Kolko 2011). Design education is facing interdisciplinary challenges, and 
students' personal attitudes and teaching applications are the two key issues (Self, Evans, Jun and Southee 2018). Changes in work and lifestyle bring new design opportunities, and design education requires the use of new technologies to support human-centered design (Budd and Wang 2017). User-centered approaches are also shifting toward a co-designed research direction (Elizabeth and Pieter 2008). There is an incompatibility between design research in practice and the one in universities (Elizabeth 2017). All of these have made a huge impact on design education.

Although there are already rich achievements in studies of design pedagogy, ID education trends, and teaching cases. There is still a lack of wide researches on the relationship between localization and internationalization and the impacts on ID education coming from Eastern and Western cultures. It is the core motivation for this study.

\section{A brief review of industrial design education in China}

Back to the early stage of the People's Republic of China (PRC) in the 1950s, scholars such as Zhifo Chen, Xunqin Pang pioneered the first modernization of Chinese design in Fine Arts based schools such as the Central College of Arts and Crafts found in 1953. Since China reopened its door in 1979, ID higher education was largely influenced by the United States, Japan, and Germany, Denmark and the UK. In the early 1980s, a group of young scholars, such as Guanzhong Liu, Mingzhi Wang, Fuchang Zhang, Jingfang Wang, Renke He, Jianghong Zhao went abroad to study under the government-funded MOE or China Scholarship Council program (the counterpart as Fulbright scholarship in USA) in North American, Europe and Japan. When they returned with their international design education experience they established new modern ID programs and adapting foreign curriculum and research methods to the Chinese higher education system. These scholars set off the first wave of modern ID education in China. All of them have become leaders in the design industry field in China today (He 2003). The ID programs they founded at the Academy of Arts and Design at Tsinghua University (the former Central Academy of Craft Art), School of Design at Jiangnan University (the former Wuxi Institute of Light Industry) and School of Design at Hunan University are all top International ID programs (CDGDC 2018).

Figure 1 shows that the colleges and universities in the United States, Japan, and European countries deeply impacted China's three universities and other ID schools during the early construction of ID undergraduate programs in China. China has been inviting "Foreign Experts" to mentor Chinese ID programs, teach classes and workshops and start exchange programs. Dr. Nagata Takashi from Chiba University and his colleagues organized one of the first ID Educator's Advanced Class in Hunan University sponsored by Japan International Cooperation Agency (JICA) in 1983. Klaus Lehmann, Dean of the Stuttgart State Academy of Art and Design (ABK-Stuttgart) in Germany, organized ID basic courses at the Central Academy of Craft Art (Wang 1985). Mr. Peter Thomson, consultant of the British Design Council lectured at the Wuxi Institute of Light Industry, promoting the concept of ID, helping and funding scholars to study ID in the UK. The MOE continues to fund "Distinguished Foreign Experts" in ID from Korea, USA, Brazil, and Europe. Since 2013, the Top Thousand Talents Plan continues to attract top ID Professors and Scholars from around the world.

From 1990 to 2010 China's ID education grew rapidly as Chinese society recognized the value of ID. The demand for ID in the Yangtze River Delta and Pearl River Delta regions increased rapidly. The Shanghai World Expo and the Beijing Olympic Games focused the world's attention on China and created explosive growth in the ID field. At the end of the 


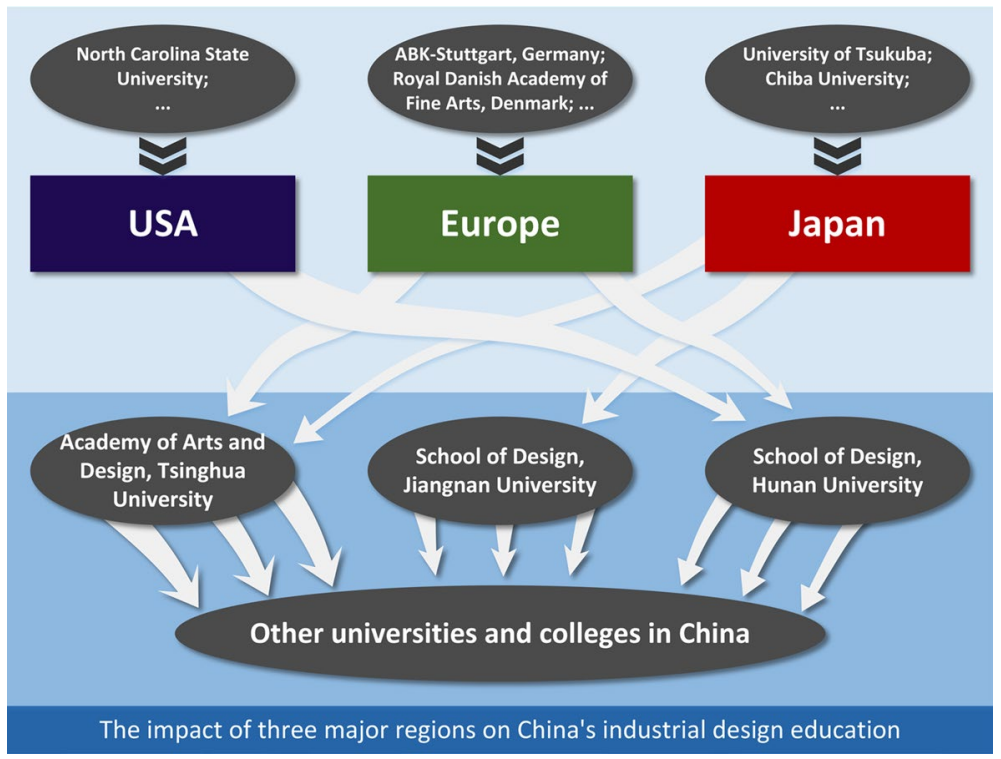

Fig. 1 The impact of three major regions on China's ID education

1990s, the MOE began to expand the admission numbers for university ID education. The number of higher education institutions offering ID programs in China grew to more than 500, with 20,000 graduates a year. However, insufficient education resources and the lack of suitable students led to a decline in the quality of graduates. China simply did not have enough young ID teachers with professional ID experience to train their students properly. Many schools simply offered courses in engineering and fine arts (Zhang and Dou 2010) expecting that a designer would emerge after 4 years. As a result, a large number of unqualified "design talents" are unable to meet the requirements of independent design and research development (Tong 2008). With the boom of Industrial Design education in China, it lacks systemic research in international community to let scholars and educators outside of the Great Wall could better understand its mechanism, opportunities and challenges.

\section{A brief review of industrial design education in USA}

Before the 1930s, manufacturing was mainly concentrated in the northern region of USA, so ID schools were also concentrated in places New York, Philadelphia, New England or to the middle west like Chicago. Carnegie Institute of Technology (now Carnegie Mellon University) founded the Department of Applied Design in the early twentieth century. In 1936, five students obtained the world's first ID undergraduate degree (Margolin 2015). During this period ID schools were influenced by the Arts and Crafts Movement in Europe. On the one hand, some art colleges study the British model in courses such as painting, drawing, color, and pattern design. On the other hand, they absorb Scandinavian traditional craftsmanship values (Clark et al. 1983).

Since the 1930s, Walter Gropius, Mies Van Der Rohe, and many European designers immigrated to USA, which promoted considerable progress in design. Large-scale 
enterprises promote the production of hundreds of products in the same group at the same time. The idea that design stimulates sales was emphasized, furthering the internationalization and globalization of American design (Margolin 2005). Raymond Rowe, Henry Earl and several well-known industrial designers appeared in this period.

After the Second World War, the idealism and experimental spirit of the Bauhaus significantly influenced the development of ID education in USA. Moholy-Nagy created the "New Bauhaus" (now the IIT Institute of Design), which advocates the unification of "art, design, technology, and industry". It and subsequent tech-based schools such as Georgia Tech, UC Berkeley, and Auburn University have inherited Bauhaus design philosophy and teaching ideas, guiding students to experiment, explore and invent materials' properties, surface effects, and space and volume by setting up basic courses (Findeli 1990). And the characteristic of studio-based teaching has become the basic paradigm for teaching most ID programs in USA.

Art-based design schools are another category, they are mostly dominated by professional designers. For example, Donald Dohner founded the Department of Industrial Design of the Pratt Institute of Art in 1935, and Edward A. "Tink" Adams founded the ArtCenter Design School in 1930. Their styles were close to market demand, emphasizing design skills and artistic characteristics. Designers they trained could adapt to commercialization and professionalization (Tenorio-Trillo 1996).

These two types of ID schools have their different characteristics, which both have their board impact on the disciplines, professions and industries in USA and the world today.

\section{Methodology}

This study includes governments, policies, institutions, operation, teachers, students, and other objects in education system, which requires "thick descriptions" of context (Geertz 1973). It is necessary to analyze the development of ID education in the social context, to discuss the training problems inside the ID school, and to compare Chinese and Western cultural context in international background. For this purpose, we conducted a systems approach (Betts 1992; Cohen et al. 2002), using methods as below.

\section{Literature review}

Literature review is a method to obtain information through surveying the literature, so as to comprehensively and correctly understand the problem to be studied (Crossan and Apaydin 2010). Analogy and comparison of the literature of industrial development, ID development, and design education in China and USA can help us better understand the context that ID undergraduate education developed in the two countries. From literature review in both Chinese and English media, we compared ranking, evaluation, accreditation, toplevel management, and national policies which would influence the education strategy of ID schools.

\section{Historical and comparative research}

Teaching practice is historical, realistic, and future. History has reflected enormous changes in societies. The study of past typical events in the order of historical development can reflect the cultural environment and social development assumptions, which is the 
basis for key decisions in current affairs (Mason et al. 1997). Cross-cultural comparative analysis can reveal the similarities and differences of people's social behavior and psychological characteristics and their development laws under different social conditions (Brislin 1976). The differences between Chinese and Western cultures affect the way college students learn ID. The globalization and international education process also accelerate crosscultural cooperation on ID field. It is helpful to discover the regularity of ID education development by reviewing the literature of design education history and the "incorporated comparison" (McMichael 1990) to the typical events or phenomena of both systems.

\section{Case studies}

The case study is a method to investigate and analyze specific research objects, to clarify the structures, characteristics and formation process (Yin and Heald 1975; Stake 2005). We surveyed the credit system and curriculum of each four design schools in China and USA, include Hunan University (China), Central Academy of Fine Arts (China), Wuhan University of Technology (China), Tianjin University (China), and ArtCenter College of Design (USA), Georgia Institute of Technology (USA), Rochester Institute of Technology (USA), Carnegie Mellon University (USA), based on the first hand materials from school chairs/ deans or program coordinators.

\section{Classification of ID education systems}

\section{Industrial design V.S. product design}

Today, both China and the United States use ID and PD in undergraduate education. From a professional point of view, the difference between ID and PD is not obvious, product designers and industrial designers play almost the same role in the industry. For the public, ID sounds more technical, engineering and academic, while PD sounds more straightforward and commercial. In 2015, the International Industrial Design Association (ICSID) officially changed its name to the World Design Organization (WDO), which reflected the evolution of ID to a broader discipline. The ID has extended from products into systems, services, experiences, and business networks, reflecting the cross-disciplinary and interdisciplinary trends through the internet and smart devices.

In China, the difference between PD and ID programs is mainly due to differences in the admission category that art schools prefer to use PD, while science and engineering colleges prefer to use ID. Typically, Art Schools grant a Bachelor of Fine Arts (B.F.A) in PD and Science schools grant a Bachelor of Engineering (B.E) in ID.

In United States, both PD and ID programs exist due to the professional requirement and the differentiated development of various schools. ID aims to improve the functionality, aesthetics, experience, and service of all created things. PD shifts to the new meaning to digital products in the boom of User Experience (UX) in tech companies. Because of the comprehensive and cross-characteristics of ID, many research institutions not only offer ID undergraduate programs but also offer master and doctoral programs with various degree types.

In both countries, schools have the freedom to set their own program concentrations, such as home appliances, furniture, toys, exhibition, transportation, which allows them to tailor their graduates to local industries. The relationship between education and local 
industries is close in China as well as in USA. Both countries have their own large-scale industries, which need corresponding education programs to support the development.

\section{Traditional dual-track mode in China}

There are two types of ID programs in China. One is the art-based program, and the other is the technology-based one. In the 1980s, about 11 professional art colleges had art-based ID programs that enrolled art candidates, and several comprehensive universities had tech-based ID programs that enrolled science and science candidates. At the beginning of this century, many comprehensive universities also began to enroll ID candidates from the art category, and the scale was growing fast. 2011 was a year of change. "Design" was upgraded to a first-level discipline, with six secondary disciplines including ID. The art-based ID programs were renamed "Product Design" and the science-based ID programs kept the name "Industrial Design".

Tech-based ID students are more suitable for comprehensive problem solving, and art-based PD students have more advantages in visual comprehension and creative expression skills. In the future, the social demand for ID is diverse. The design will have a wider connection with the whole society (Hang 2011). The cultivation of Chinese ID talents should have creativity, operation, understanding, global vision and international experience (Yuan and Zhang 2018).

Today, the differences between the undergraduate programs of ID and PD in China are mainly concerned with the source of students and the structure of courses. Students of art have a good foundation in drawing and model making. They have good abilities in form, color and visual language with strong communication and storytelling skills expression. However, they have a poor foundation in mathematics, science, and technology, and are difficult to be competent in the innovation work that needs to integrate multidisciplinary knowledge. Students of science have advantages in system analysis, quantitative research, and technical application. However, their creative thinking, innovation ability are easily constrained by inherent thinking. Their visual communication and storytelling are weak.

\section{The flexible dual-track system in USA}

ID education in USA is also a dual-track training of art and technology. Some ID programs are in art schools, while others are in comprehensive universities and technology universities. Since the 21 st century, ID programs of comprehensive universities in the US have developed rapidly, mainly due to the wealth of cutting-edge scientific resources and close interdisciplinary cooperation. These programs not only emphasize the systematic of courses, focusing on effective linking between courses and the cultivation of hands-on ability but also emphasize the application of science and technology and the commercial transformation of design, focusing on multidisciplinary cooperation and teamwork (Zhang 2013). For example, the Media Lab of the Massachusetts Institute of Technology is dedicated to applying design and technology to solve social problems (Robert 2006). The design program of Carnegie Mellon University focuses on future-oriented frontiers such as service design, social innovation, integrated innovation for products and services, and cross-integration with engineering, business, and management. 


\section{Ranking, evaluation, and certification}

\section{Educational evaluation in China}

The Chinese government (Ministry of Education) has never published university or undergraduate program rankings, and it also claimed that it does not support the official university rankings. At present, there are also some independent institutions in China to conduct university rankings or undergraduate program rankings, such as "Cuaa.net", "Shanghai Ranking's Academic Ranking of World Universities" (ARWU), "Chinese University Evaluation" (Wu Shu-Lian Ranking), and Rankings by several universities (Nanjing University, Wuhan University, and Shanghai Jiao Tong University). However, due to the incompleteness of statistics, opacity and commercial interests, these rankings are more controversial and are not recognized by the public. Fortunately, a discipline evaluation which is organized by the Ministry of Education of China is valuable. It is an overall level assessment of all first-level disciplines with master and doctoral degrees. It evaluates and grades the top $70 \%$ of all the disciplines in mainland China. Due to the integrity of the data and its official background, all colleges and universities attach great importance to it.

The National Discipline Assessment conducted by the Ministry of Education of China in 2017 was the fourth round of assessment. It was the first time to assess the design discipline. A total of 94 universities with an undergraduate program in design participated in the evaluation, including 16 universities with a doctoral degree in design. In China, schools that have the design postgraduate programs generally have built undergraduate majors such as ID, environmental design, and visual communication design. Among the four indicators of this subject evaluation system, the faculty and resources, the quality of talent training, and the level of scientific research are the important factors that directly affect undergraduate programs, so it can basically reflect the undergraduate education level of design schools.

In Table 1, the top levels of universities in the assessment of design subjects are listed (CDGDC 2018) which is a non-profit program organized by China Academic Degrees and Graduate Education Development Centre (CDGDC). China University Subject Rankings (CUSR) is in the principle "voluntary and free participation" and aims to assist the participating universities and institutions to be acquaintance with the merits and demerits of their subject constructions. The results show that Tsinghua University, China Academy of Art, Jiangnan University, Hunan University, and other universities were ranked in the forefront. Among the 37 colleges and universities, except for the Communication University of China, there are 18 colleges with art-based PD programs, 11 universities with techbased ID programs, and 7 universities with both types of programs.

This evaluation can promote the active competition of colleges and universities, and can greatly affect the financial investment, teacher resources and student source level of colleges and universities. It is difficult to predict whether China will launch an official undergraduate education ranking for ID programs in the near future. However, undergraduate teaching as the foundation of the university will continue to be valued by Chinese schools. In addition, there will be promotion policies to improve undergraduate teaching in the future. 
Table 1 China University Subject Rankings (CUSR) of design by 2017

\begin{tabular}{|c|c|c|}
\hline Name of university & Level & $\begin{array}{l}\text { Industrial } \\
\text { (product) } \\
\text { design program } \\
\text { feature }\end{array}$ \\
\hline Tsinghua University & $\mathbf{A}+$ & Art-based \\
\hline China Academy of Art & $\mathbf{A}+$ & Art-based \\
\hline China Central Academy Of Fine Arts & $\mathbf{A}$ & Art-based \\
\hline Tongji University & $\mathbf{A}$ & Tech-based \\
\hline Soochow University & $\mathbf{A}-$ & Art-based \\
\hline Jiangnan University & $\mathbf{A}-$ & Both have \\
\hline Nanjing University of the Arts & $\mathbf{A}-$ & Art-based \\
\hline Zhejiang University & A- & Tech-based \\
\hline Hunan University & $\mathbf{A}-$ & Tech-based \\
\hline Beijing Institute of Fashion Technology & B+ & Tech-based \\
\hline Communication University of China & B+ & $\begin{array}{l}\text { Art-based } \\
\text { (No ID/PD } \\
\text { Program) }\end{array}$ \\
\hline Shanghai Jiao Tong University & $\mathbf{B}+$ & Tech-based \\
\hline Donghua University & $\mathbf{B}+$ & Both have \\
\hline Jingdezhen Ceramic Institute & $\mathbf{B}+$ & Art-based \\
\hline Wuhan University of Technology & B+ & Both have \\
\hline Guangzhou Academy of Fine Arts & B+ & Art-based \\
\hline Sichuan Academy of Fine Arts & B+ & Art-based \\
\hline Xian Academy of Fine Arts & $\mathbf{B}+$ & Art-based \\
\hline Beijing Institute of Technology & B & Both have \\
\hline Luxun Academy of Fine Arts & B & Art-based \\
\hline Harbin Institute of Technology & B & Tech-based \\
\hline Shanghai University & B & Art-based \\
\hline Southeast University & B & Art-based \\
\hline Hubei Institute of Fine Arts & B & Art-based \\
\hline Guangxi Arts University & B & Art-based \\
\hline Sichuan University & B & Tech-based \\
\hline Shandong University of Arts \& Design & B & Tech-based \\
\hline Guangdong University of Technology & B & Tech-based \\
\hline Beijing Institute of Graphic Communication & B- & Both have \\
\hline Tianjin Academy of Fine Arts & B- & Art-based \\
\hline Nanjing Normal University & B- & Art-based \\
\hline Zhejiang University of Technology & B- & Tech-based \\
\hline Zhejiang Sci-Tech University & B- & Both have \\
\hline Huazhong University of Science and Technology & B- & Art-based \\
\hline Wuhan Textile University & B- & Art-based \\
\hline Hubei University of Technology & B- & Both have \\
\hline Northwestern Polytechnic University & B- & Tech-based \\
\hline
\end{tabular}

In 2017, the Ministry of Education of China completed the fourth round of evaluations for disciplines across mainland China. The top $70 \%$ of the disciplines are divided into 9 levels. The first $2 \%$ (or top 2) is $\mathrm{A}+, 2 \%$ to $5 \%$ is A (excluding $2 \%$, the same below), $5 \%$ to $10 \%$ is $\mathrm{A}-, 10 \%$ to $20 \%$ is $\mathrm{B}+$, and $20 \%$ to 30 $\%$ Is B, $30 \%$ to $40 \%$ is B-, $40 \%$ to $50 \%$ is $\mathrm{C}+, 50 \%$ to $60 \%$ is C, and $60 \%$ to $70 \%$ is C-. There are about 96 schools of design attended the evaluation in this round. Only schools from A+ to B- are indicated in this table. Colleges and universities with the same evaluation results sorted in no particular order 


\section{Ranking of design schools in USA}

Similar to China, the United States does not have an official university ranking or professional ranking. However, its commercial university rankings are developed and diverse, such as USNEWS, Niche, Collegeboard, Collegevaluesonline, and so on. They are commercial activities that mainly serve the students and parents. Admissions in American universities are application-based. Economic factors (such as tuition fees, scholarships, employment status) and geographic location determine the student's intention to apply. So the rankings are not the most prioritized facts when choosing a university.

Among ranking systems, USNEWS has the strongest influence, but it had no rankings for design schools and ID undergraduate programs. In other ranking versions, Niche (2019) had a comprehensive ranking of colleges with ID and PD Degrees in USA. It performed the assessment from 6 parts: Academics, Value, Diversity, Campus, Athletics, and Party Scene. Collegevaluesonline (2018) evaluated over 60 schools and selected the top 30 most valuable undergraduate ID degrees, which was useful for students and their families. Table 2 shows the top best and the top valuable ID undergraduate degrees in USA.

Table 2 Best and valuable ID undergraduate degrees in USA

\begin{tabular}{|c|c|c|c|}
\hline & Schools & $\begin{array}{l}\text { Evaluation by } \\
\text { Niche }\end{array}$ & $\begin{array}{l}\text { Rating by } \\
\text { Collegevalue- } \\
\text { sonline }\end{array}$ \\
\hline 1 & Carnegie Mellon University & $\mathrm{A}+$ & Rating: 10 \\
\hline 2 & Georgia Institute of Technology & $\mathrm{A}+$ & Rating: 14 \\
\hline 3 & Virginia Polytechnic Institute and State University & $\mathrm{A}+$ & Rating: 8 \\
\hline 4 & University of Illinois at Urbana-Champaign & $\mathrm{A}+$ & Rating: 9 \\
\hline 5 & Brigham Young University & $\mathrm{A}+$ & Rating: 10 \\
\hline 6 & University of Washington & $A+$ & - \\
\hline 7 & Purdue University & $\mathrm{A}+$ & Rating: 9 \\
\hline 8 & The Ohio State University & $\mathrm{A}+$ & - \\
\hline 9 & North Carolina State University & $\mathrm{A}+$ & Rating: 9 \\
\hline 10 & Clemson University & A & - \\
\hline 11 & Iowa State University & A & Rating: 13 \\
\hline 12 & Syracuse University & A & - \\
\hline 13 & Auburn University & A & Rating: 8 \\
\hline 14 & Rhode Island School of Design & A & - \\
\hline 15 & Arizona State University & A & Rating: 12 \\
\hline 16 & University of Utah & A & - \\
\hline 17 & University of Cincinnati & $A-$ & - \\
\hline 18 & Rochester Institute of Technology & $\mathrm{A}-$ & Rating: 12 \\
\hline 19 & Drexel University & $A-$ & Rating: 9 \\
\hline 20 & University of Houston & $A-$ & Rating: 11 \\
\hline 21 & Appalachian State University & $A-$ & Rating: 8 \\
\hline 22 & California State University - Long Beach & $\mathrm{A}-$ & Rating: 9 \\
\hline 23 & Cedarville University & $A-$ & Rating: 11 \\
\hline 24 & University of Illinois at Chicago & $A-$ & Rating: 9 \\
\hline 25 & Agnes Scott College & $A-$ & 1 \\
\hline
\end{tabular}


Undergraduate program rankings and university rankings are of greater concern to students. The ID and PD programs occur in two ranking categories, the engineering program category, and the fine art schools category. The interdisciplinary characteristic of ID will be more obvious in the future. It will bring greater challenges to assessment agencies and universities.

\section{Certification mode in USA}

USA does not have centralized control and management of education at all levels, which is different from China. NASAD plays an important role in designing educational quality certification, effectively promoting and ensuring that universities have qualified schooling conditions and teaching standards. There are about 79 colleges and universities that teach ID in the U.S, and 49 of them are the Association of Schools of Art and Design (NASAD) accredited (IDSA 2019).

NASAD sets standards for different levels of talent development in art and designrelated programs and provides guidance, advice, and assistance in a targeted manner. It evaluates the teaching ability of colleges and universities from three general standards, professional standards, and general education. Firstly, NASAD makes requests to schools in the respects, such as administrative management, curriculum, teaching quality, number of teachers, teacher standards, working conditions, financial status, hardware facilities, library resources, student learning conditions, learning-related resources, and advanced courses in art and design, etc. Furthermore, NASAD provides guidance on the ability of the human, material, and financial resources to support the design schools, as well as the development of design knowledge and skills, and the interaction of design students and professionals to promote the academic environment in which schools provide good design research (NASAD 2019).

Because NASAD only makes the decision of approval or disapproval, it does not rank the rankings of each member institution, which makes the university can diversify and develop its own characteristics in terms of talent training orientation, school running concept, school running mode, etc.

\section{Comparison of curriculum}

\section{Credit system}

The credit system was first established at Harvard University in the United States at the end of the nineteenth century. China began trials in some universities in the late 1970s. American universities recommend a 3 -h study time per class for each credit. There are about 14-16 weeks per semester, so one credit is approximately $42-58 \mathrm{~h}$ of study. In China, one credit is equal to about 16 classroom hours, but there is no explicit requirement for the time of the study. Students can get credits when they pass the course exam. In addition, the exam form of many ID courses is to submit design works, and there are no specific criteria for evaluation. Therefore, many students do not need to spend a lot of extracurricular studies to pass course examinations and get credits.

In Table 3, eight typical ID schools in China and USA were investigated and the aspects were compared such as academic system, number of credits, degree category, entry requirements, and student-teacher ratio. ID schools in USA pay more attention to student 


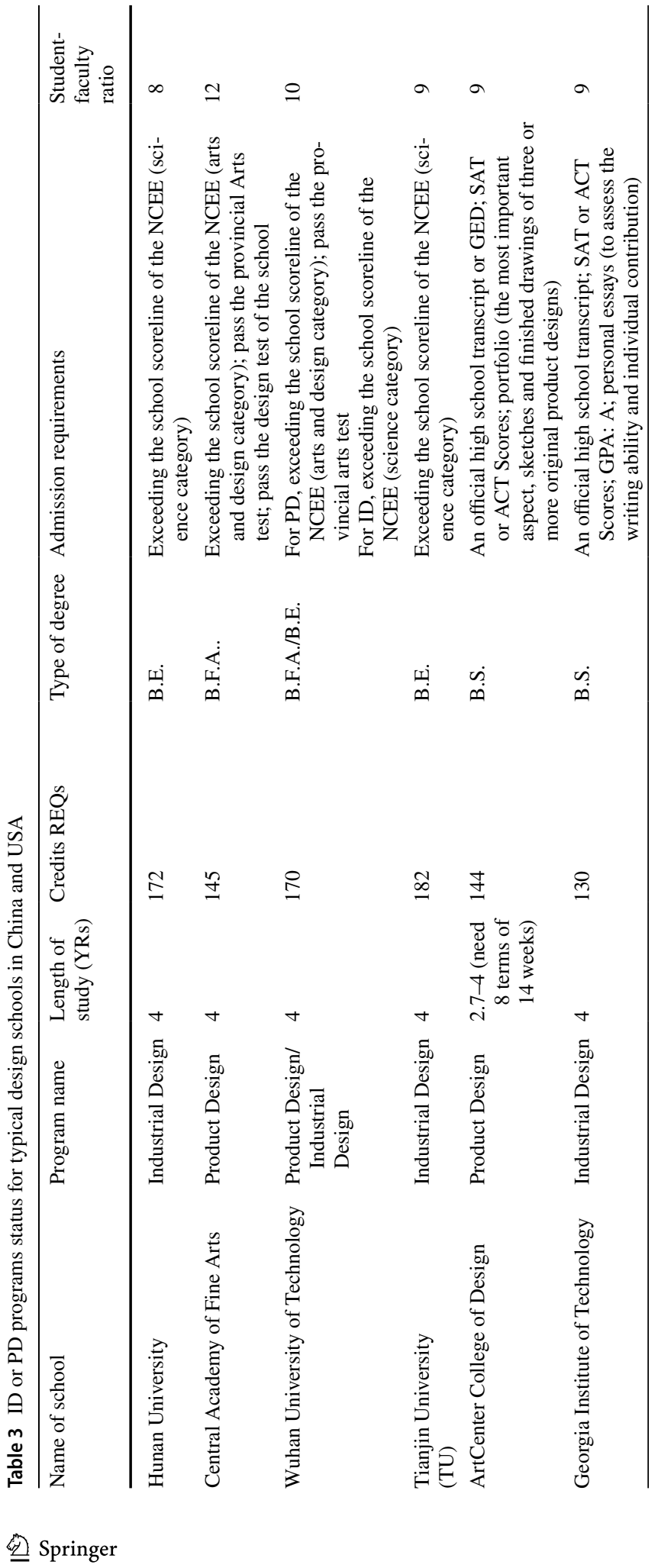




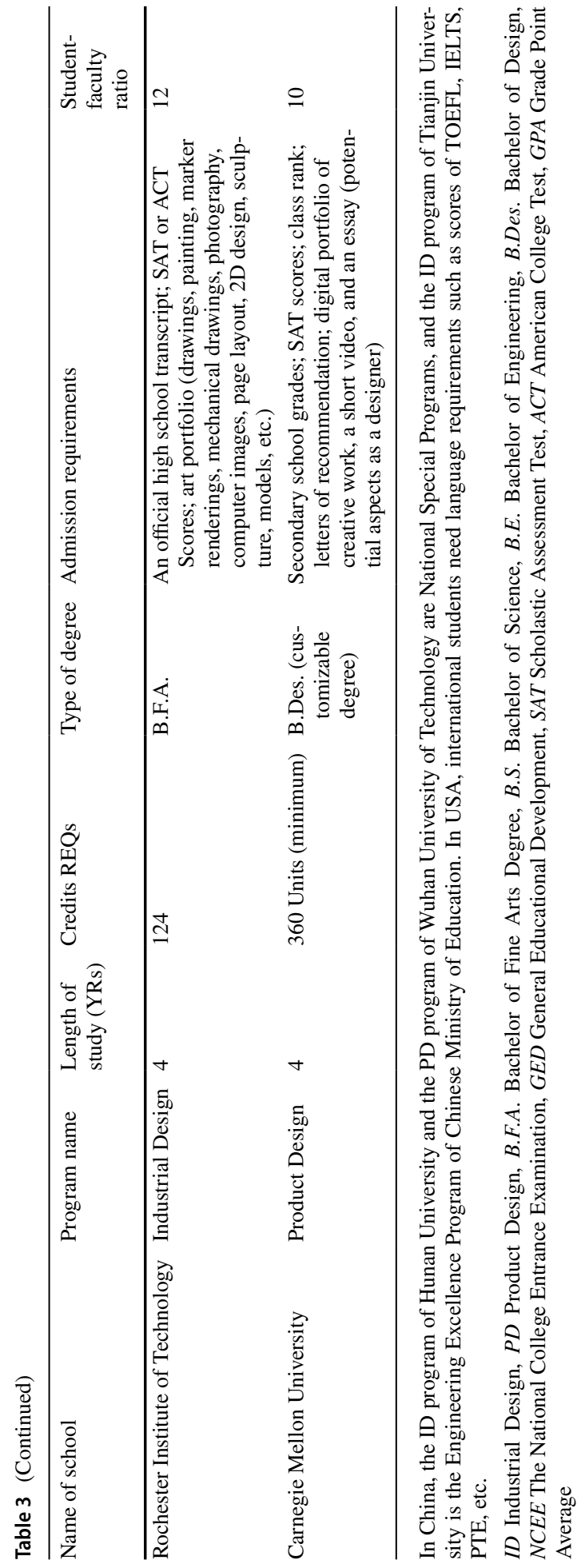


development, with more educational resources, flexible time planning, normative credit requirements, and suitable admission ways. The specific analysis is as follows:

Firstly, the number of credits in Chinese schools is higher than that in American schools. All of the eight schools have basically 4 years of schooling. Except for the Unit system of Carnegie Mellon University, ArtCenter College of Design, Georgia Institute of Technology, and Rochester Institute of Technology use the credit system, and the average course credit of ID is 132.67. Hunan University, Central Academy of Fine Arts, Wuhan University of Technology, and Tianjin University of China have an average credit of 167.25, which is $26 \%$ higher than the US. So the credits of two countries' ID programs can roughly exchange in this way: "One credit in China equals 0.8 credits in USA".

Secondly, there is no significant difference in the types of degrees between China and USA, but the latter is more flexible. The situation in USA is similar, but the difference is that Carnegie Mellon University has a special Bachelor's degree in Design, and students can customize the degree by own needs and intention, which is a positive exploration.

Thirdly, the admission system of the two countries is different. Most Chinese ID students are not familiar with the ID program before entering the university, and they are easy to passively study and lack career pursuit. It is mainly caused by China's unified national college entrance examination and admissions system that design schools cannot influence the enrollment too much. In most cases, they even cannot fully review students' portfolios before send offers out. American students learn about the undergraduate programs and prepare the required knowledge and experience before they enter the university, which can help them to develop their studies in college.

Finally, the teachers of ID schools in USA are more professional to ones in Chinese schools, and they have a wider practice background in the field of design. The studentfaculty ratios of these eight ID schools are not much different, but due to all tenured/ tenure-track system and the short development history of ID education, most teachers in China lack the design experiences. In USA, ID schools employ a large number of part-time professors, professors of practice, and professional designers as well as traditional fulltime professors. The faculty can provide students with professional methods and valuable experience.

\section{Course features}

In the information age, new participants, new initiatives, and new thinking are more and more important for design activities. Collaborative projects and research sources need to be integrated into design courses, and design schools need to enhance the partnerships with companies (Boyarski 1998). Table 4 summarizes the main features of the ID curriculums between China and USA. The studio is the typical course of ID programs in USA and the curriculums of China are relatively segmented.

In the ID curriculum of USA, the studio is the core and most characteristic course, which can enhance students' actual design ability. Six or more studios are generally scheduled in the 4 years study, and the difficulty of the course is gradually increasing. The studio focuses on "how to design" and introduces the complete design process into the classroom such as design research, idea inspiration, product development, etc. Professors direct students' design process and help them to enhance the abilities and conscious of innovative thinking, design philosophy, opportunity mining, business services, market discipline, and environmental responsibility. 
Table 4 Features of design courses in USA and China

\begin{tabular}{|c|c|c|}
\hline Features & The "Studio" system in USA & The "Segmented" system in China \\
\hline Advantage & $\begin{array}{l}\text { 1. Emphasize on the discovery of design } \\
\text { opportunities. Focus on commercial design } \\
\text { services, traditional skills, integrated media, } \\
\text { and new technologies } \\
\text { 2. More attention to various presentation } \\
\text { methods of design (drawings, models, and } \\
\text { videos), production of models and proto- } \\
\text { types with different functions at various } \\
\text { stages, and visual presentation } \\
\text { 3. Constantly repeating the design process. } \\
\text { Integrate design methods, materials technol- } \\
\text { ogy, commercial property, and multi-disci- } \\
\text { pline knowledge to design practice } \\
\text { 4. Emphasis on practice, cooperation, and } \\
\text { collaborative work. Design works are highly } \\
\text { completed } \\
\text { 5. Graduates have strong leadership, creativ- } \\
\text { ity, curiosity, management skills, and } \\
\text { professional confidence }\end{array}$ & $\begin{array}{l}\text { 1. Pay attention to the comprehen- } \\
\text { siveness of knowledge elements, } \\
\text { and emphasize the training of } \\
\text { skills such as sketching, draw- } \\
\text { ing, computer performance, and } \\
\text { model making } \\
\text { 2. Be sensitive to new design fields } \\
\text { and directions such as sustainabil- } \\
\text { ity design, service design, social } \\
\text { innovation, etc. Often update } \\
\text { the training plan and adjust the } \\
\text { course content } \\
\text { 3. Design projects and international } \\
\text { design competitions are addition- } \\
\text { ally arranged. Design capabilities } \\
\text { may be improved for those have } \\
\text { participated }\end{array}$ \\
\hline Weakness & $\begin{array}{l}\text { 1. The ID curriculum is stable. The lack } \\
\text { of change may affect the updating of the } \\
\text { course content } \\
\text { 2. There are uncertainties factors for students' } \\
\text { research ability and career development } \\
\text { ability }\end{array}$ & $\begin{array}{l}\text { 1. Limited ability to design integra- } \\
\text { tion. Not confident enough for } \\
\text { a design career. There is a gap } \\
\text { between knowledge and applica- } \\
\text { tion } \\
\text { 2. Limited understanding of com- } \\
\text { mercial design. Not easy to find a } \\
\text { breakthrough in the commerciali- } \\
\text { zation of innovative direction } \\
\text { 3. Limited ability to deepen design } \\
\text { options. Insufficient integration } \\
\text { ability on scientific, technical and } \\
\text { commercial resources } \\
\text { 4. Mostly passive learning. Limited } \\
\text { ability to explore. Limited aware- } \\
\text { ness of continuing to learn }\end{array}$ \\
\hline
\end{tabular}

NASAD (2019) pays special attention to the professional ability of students to receive education and work experience. ID undergraduate programs of USA provide students with variable opportunities for school-enterprise cooperation. For example, University of Cincinnati (2016) requires students to participate in cooperative education for a certain period of time.

Correspondingly, ID curriculums in China are more traditional, with more emphasis on teachers, textbooks and classrooms. Firstly, many ID undergraduate programs still stay in the traditional "Teaching to Learning" knowledge transfer model, focusing on knowledge teaching and skill training. Then, most of the course elective systems are still fossilized, which gives fewer options for students. The metaphysical knowledge elements are emphasized, while the course organization is not reasonable enough. Furthermore, they lack integrated courses aimed at career requirements and commercial applications. The lack of professional practice and experience makes it difficult for students to build professional confidence. 
Although there are some problems, China's ID education has some advantages and may be reflected in the next few years. The Chinese government is actively leading and promoting ID industrialization in the past decade. A large number of government or business organization design competitions and activities have emerged, which has enhanced the industry and people's understanding of ID. More importantly, through competition and reflection, students' abilities can be improved at the level of cognition, technology, and expression. Furthermore, many ID undergraduate programs are becoming autonomous and active in management and adjustment. The training plans are adjusted year by year, and the curriculums are continuously updated, which can quickly adapt to new changes in the academic and new demands of the industry. For example, many schools have added required courses such as smart product design, smart home design, service design, experience design, and sustainable design, as well as elective courses such as design computing, $3 \mathrm{D}$ print technology, big data, and artificial intelligence.

\section{Yearly schedules}

The annual schedule of Chinese ID schools is relatively stable and consistent, but there are no planned elective courses and practical opportunities for holidays. ID schools in USA are more diverse and flexible, and students have more time and opportunity to choose to study or practice. Figure 2 shows the yearly schedule of the general ID Schools in China and USA.

Chinese colleges and universities generally run the two-semester system, two sixteen to eighteen weeks of teaching period for the fall and spring semester. There are totally about 3 months for winter and summer vacations, a week of holiday in the National Day holiday in early October, and several 1-day holidays such as Labor Day and Mid-Autumn Festival. Generally, no elective courses are offered on holidays. Teachers usually encourage students to participate in internships, design practices, competitions, which are not mandatorily required.

Most ID schools in USA also run the semester system. The fall and spring semesters are each about 14 to 18 weeks. The length of the single-semester in USA is slightly lower than that of China, however, it has higher course requirements and higher strength learning. Some schools offer summer programs of about 6 weeks, mainly offering elective courses. There usually are about 3 months for the summer holidays and about 3 weeks for the Christmas and New Year winter holidays, and totally about 2 weeks for Spring breaks and Thanksgiving holidays. There are also some 1-day public holidays, such as Labor Day,
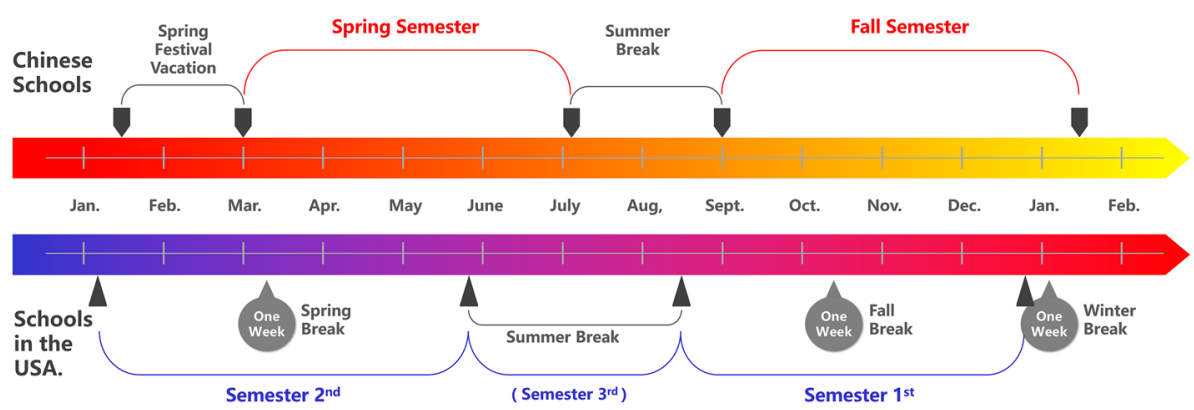

Fig. 2 The difference of the semester schedule between USA and China 
Independence Day, Columbus Day, etc. ID schools in USA offer flexible options for students, such as seminars, international academic travel, company internships, collaborative projects, etc., to suit the different needs of different students.

In addition to the knowledge and ability of art and presentation, technology and engineering, future industrial designers need to have abilities to integrate experience in economic, information, life, culture, and market. With these, ID Schools in China needs to do more work in the quality control of class courses, the flexibility of teaching and practice, and the diversified holiday programs to promote the students.

\section{Impact by culture and environment}

Culture and environment have an important influence on design education. Culture determines the way people think and behave. In general, Chinese students are not active enough and not confident enough in a new environment. They are willing to accept the inherent things and respect professors, but not dare to break through the fixed frames of the education system. American students are independent and have a critical thinking spirit. And they dare to say, dare to challenge, and are willing to take more responsibility and initiatives.

Design education should be based on local culture, while it should also consider the cross-cultural influence brought about by the trend of economic internationalization (Mejlhede 2015). Both the large enterprises and higher education are developing towards internationalization, which raises new requirements for design students. It needs them to develop cross-cultural awareness and team collaboration under international settings. The life experience, study, and design practice in local are good training paths. Studying abroad creates an embedded experience for students (Deardorff 2009). But they need to insist on the cultural norms and values in the current cultural context when they study abroad. Instead of judge design affairs in the cultural framework of themselves.

Under the globalization trend, international talents should become global citizenship to gain adaptability and competitiveness. And cultural capital has become an important attribute of the ability of ID students. ID schools need to create a more diverse approach for students to participate in international learning and collaboration to understand the inherent differences between cultures. ID students should also build cross-cultural awareness and actively participate in international learning. In China, ID programs of Tsinghua, Hunan, Tongji, and some other Universities have taken international students rate as an important development direction. Their graduates have entered multinational companies from Volkswagen, Google, Samsung to Mircosoft, or Chinese well-known companies that have extensive international businesses such as Huawei, Baidu, Alibaba, Lenovo or Haier. Meanwhile, American students are more willing to move to the Bay area with diverse cultures or even Europe and Asia to work with the global design industry.

At another level, campus and teaching environments take a potential impact on creativity and design education. Creative spaces require all five types of space: personal, collaboration, presentation, making, intermission (Thoring et al. 2018). American universities pay great attention to the supporting of the historical, cultural and artistic environment to support design education. Exhibition halls, art museums, galleries, shops, and other resources offer a multi-dimensional cultural and innovative atmosphere. It helps students to develop independent ideas, enhance abilities of aesthetics and expression, and construct cultural self-confidence. 
In contrast, most Chinese ID schools focus on knowledge learning and academic resources, such as new courses, highly educated teachers, lab equipment, and teaching space. The advantage is to keep track of cutting-edge knowledge. While the disadvantage is the lack of a free, critical, and creative study environment. Changes have begun to appear, and some comprehensive universities have pay attention to the construction of cultural and artistic environments. Tsinghua University, Zhejiang University, Wuhan University of Technology, and other schools began to build museums, art museums, and other types of cultural bodies on the campus.

\section{Reflection}

This research focused on the ID education of USA and China. China has experienced three development stages of unknown exploration, transplanting reference and rapid growth in the past 40 years. In the early years, influenced by universities in the United States, Japan, and European countries, some returning scholars started design teaching reforms in colleges and universities, which caused a large number of other Chinese universities to learn and emulate. In the past 20 years, China's design education has developed rapidly and has become the world's largest education system. Now they are actively following the frontiers of some disciplines with their universities' ranks rapidly climbing worldwide, as well as exposing some of the problems of such a fast-growing education system. It may be a good time to reflect on how to improve their ID education system to address the challenges mentioned above. We tried to reveal the main factors that influence the ID undergraduate education in the background of the globalization trend as below:

1. China's ID undergraduate education consists of two categories: art-based and techbased, which is very similar to that of the United States. However, apart from some colleges with a long history of running schools and some comprehensive universities with comprehensive ability, the homogenization of design programs in many colleges and universities is obvious, lacking diversity and individuality. The credit system, admission way, studio curriculum and the certification of ID schools in USA are more mature and diverse. Graduates are more competent and professional in design services. ID schools in China need to enhance the credit system, teacher competency development, admissions system, talent training goal setting, curriculum structure, and teaching methods, which is beneficial to equivalent credits and degree with other countries and promote international education cooperation.

2. Both USA and China did not like to take the official or third-party ranking of design education. University and undergraduate program rankings in USA are mostly business activities. The main customers are students and their parents. Except for the academics, the geographical location, price, and degree value all influent their choices. In China, the most important discipline assessment determines the government's investment, management, and guidance to universities, while it may cause schools' homogenization and polarization. It is worth to think about how the official or third-party assessment or ranking can enhance the education level and promote the diversity development of ID schools in China.

3. The openness of design education in China is becoming more and more obvious. Due to the wide range of design education issues in China, there are still many problems that we don't know enough and need further research. One of the questions is about how to select suitable design students based on the Chinese college entrance examination system in 
the dual-track ID education system. Another valuable question is how to integrate Chinese design education into the global education system and how undergraduate, masters and doctoral degrees are equivalently certified by other countries, which requires more and more extensive research and practical work.

4. The studio course is the obvious feature of ID education in USA. Lecturers, students, and collaborators establish a process of co-design ecosystem (Dorta et al. 2016). In the teaching activity, teachers need to pursue moral development for students, stakeholders and themselves (McDonald and Michela 2019). ID teaching in China needs to focus on the structure and organization of the core curriculum, and build an open and creative studio environment. Exploratory-oriented courses and business-oriented courses need to be purposeful and different. ID schools should integrate enterprise cooperation projects into undergraduate courses, establish a school-enterprise cooperation mechanism, and guide students to participate in co-design practices. Teachers also need to organize studio teaching flexibly, improve students' active participation, and encourage criticism.

5. It is important to pay attention to the potential impact of culture and the environment. The innovative nature of design activities dictates the need for bold attempts. Pursuing the spirit of adventure and enhancing professional interest are the key factors for design students' development. Teachers also need to apply the spirit of innovation to the curriculum (Macdonald and MacLeod 2018). ID schools in China need to create a free learning environment in art and humanities, which benefits students' spirit of thinking, exploration, and innovation. They also need to change at the balance between teaching and learning, expression and creation, discussion and criticism, and globalization and localization and make students more professional, international and confident.

ID education not only needs to adapt to the lifestyle change driven by technology development but also needs to pay attention to the change from industry and social architecture. Comparing with USA, China's current ID education is developing rapidly, but the overall level of undergraduate education is uneven. Only a small number of colleges and universities have risen significantly in the international academic rankings, and a large number of them have more obvious problems in the ID undergraduate education.

\section{Limitations}

One limitation of the present study is that more researches lie in a macro-level view and be not sufficient enough at a micro-level perspective. This raises questions about the possible influence of the potential trend of globalization on ID students, instructors, and their practice activities in different cultures. Another limitation is the lack of research on more ID education systems of other representative countries, which would be a good supplement of the present study.

Some European countries have different education concepts and cultural backgrounds than China and the United States. In the East, Japan and South Korea also have different paths in developing ID education. This raises questions about the development directions at national, university and school levels to adapt to the national or global competitions in the future. The above two points should be addressed in future work. 


\section{Conclusion}

We hope that the analytical model of ID undergraduate education can provide valuable insights for government departments, school administrators, academics, professors, students, etc. involved in the design of undergraduate education. Given that the study focused on ID education in China and USA, which can represent not only the characteristics of Eastern and Western but also the features of developing and developed countries, we argue that the results are generalizable and can be referenced by other institutions. Educational management and important decisions at the national and university levels vary according to cultural differences and differences in personal philosophy. Some countries or schools have been adhering to some characteristics in design education, and the impact of these activities on student development requires further research and evaluation. We are aware that broader studies and typical case studies are necessary to further refine and complement this model framework.

Acknowledgments This work was initially carried out with the support by the China Scholarship Council Foundation (201806955004).

Open Access This article is licensed under a Creative Commons Attribution 4.0 International License, which permits use, sharing, adaptation, distribution and reproduction in any medium or format, as long as you give appropriate credit to the original author(s) and the source, provide a link to the Creative Commons licence, and indicate if changes were made. The images or other third party material in this article are included in the article's Creative Commons licence, unless indicated otherwise in a credit line to the material. If material is not included in the article's Creative Commons licence and your intended use is not permitted by statutory regulation or exceeds the permitted use, you will need to obtain permission directly from the copyright holder. To view a copy of this licence, visit http://creativecommons.org/licenses/by/4.0/.

\section{References}

Betts, F. (1992). How systems thinking applies to education. Educational Leadership, 50(3), 38-41.

Boyarski, D. (1998). Education: Designing design education. SIGCHI, 30(3), 7-10.

Brislin, R. W. (1976). Comparative research methodology: Cross-cultural studies. International journal of psychology, 11(3), 215-229.

Buchanan, R. (1992). Wicked problems in design thinking. Design Issues, 8(2), 5-21. https://doi. org/10.2307/1511637.

Budd, J., \& Wang, W. (2017). Industrial design education: Taming technology to enhance user experience. Archives of Design Research, 30(3), 17-27.

CDGDC. (2018). China University Subject Rankings. China Academic Degrees and Graduate Education Development Centre. http://www.chinadegrees.cn/xwyyjsjyxx/xkpgjg/2016phden/index.shtml . Retrieved April 23, 2019.

CHESICC. (2019a). Introduction of the undergraduate discipline "Industrial Design". China Higher Education Student Information and Career Center. https://gaokao.chsi.com.cn/zyk/zybk/speciality Detail.action?specialityId=73384212. Retrieved April 15, 2019.

CHESICC. (2019b). Introduction of the undergraduate discipline "Product Design". China Higher Education Student Information and Career Center. https://gaokao.chsi.com.cn/zyk/zybk/specialityDetai 1.action?specialityId=421209035. Retrieved April 15, 2019.

Cincinnati. (2016). Co-op. University of Cincinnati. https://www.uc.edu/campus-life/careereducation/ get-experience/co-op.html. Retrieved August 29, 2019.

Clark, J., et Ali, R. J. C., Clark, R. J., Belloli, A. P., David, D., De Long, D. G., et al. (1983). Design in America: The Cranbrook vision, 1925-1950. Metropolitan Museum of Art.

Cohen, L., Manion, L., \& Morrison, K. (2002). Research methods in education. London: Routledge. 
Collegevaluesonline. (2018). Industrial design degrees: Top 30 (undergrad). https://www.collegeval uesonline.com/rankings/industrial-design-degrees-top-undergraduate/. Retrieved February 23, 2019.

Crossan, M. M., \& Apaydin, M. (2010). A multi-dimensional framework of organizational innovation: A systematic review of the literature. Journal of Management Studies, 47(6), 1154-1191.

Deardorff, D. K. (2009). Intercultural competence. Thousand Oaks, CA: Sage.

Dorta, T., Kinayoglu, G., \& Boudhraâ, S. (2016). A new representational ecosystem for design teaching in the studio. Design Studies, 47, 164-186. https://doi.org/10.1016/j.destud.2016.09.003.

Elizabeth, B. S. (2017). Design research at the crossroads of education and practice. She Ji: The Journal of Design, Economics, and Innovation, 3(1), 3-15. https://doi.org/10.1016/j.sheji.2017.05.003.

Elizabeth, B. S., \& Pieter, J. S. (2008). Co-creation and the new landscapes of design. CoDesign, 4(1), 5-18.

Findeli, A. (1990). Moholy-Nagy's design pedagogy in Chicago (1937-46). Design Issues, 7(1), 4-19.

Friedman, K. (2012). Models of design: Envisioning a future design education. Visible Language, 46(12), $132-133$.

Geertz, C. (1973). The interpretation of cultures (Vol. 5019). New York: Basic books.

Hang, J. (2011). Chinese design and Bauhaus-Misreading and conscious misreading. Art \& Design Research, 48(2), 76-80. (in Chinese).

He, X.-Y. (2003). Import, digest and create: Industrial design education in China. Art \& Design, 126(10), 90-91. (in Chinese).

Ilhan, A. O. (2017). Growth of undergraduate education in design in the United States, 1988-2012. Design Issues, 33(4), 17-29. https://doi.org/10.1162/DESI_a_00458.

Industrial Design Society of America (IDSA). (2019). ID schools. http://www.idsa.org/education/idschools/. Retrieved March 5, 2019.

Kolko, J. (2011). The conflicting rhetoric of design education. Interactions. https://doi. org/10.1145/1978822.1978840.

Kolko, J. (2012). Changing the career outcomes of design education. Interactions, 1, 1. https://doi. org/10.1145/2090150.2090169.

Macdonald, I., \& MacLeod, M. (2018). Design education without borders: How students can engage with a socially conscious pedagogy as global citizens. International Journal of Art \& Design Education, 37(2), 312-324. https://doi.org/10.1111/jade.12117.

Margolin, V. (2005). A world history of design and the history of the world. Journal of Design History, $18(3), 235-243$.

Margolin, V. (2015). World history of design (Vol. 2). London: Bloomsbury Publishing.

Mason, R. O., McKenney, J. L., \& Copeland, D. G. (1997). An historical method for MIS research: Steps and assumptions. MIS Quarterly, 21(3), 307-320.

McDonald, J. K., \& Michela, E. (2019). The design critique and the moral goods of studio pedagogy. Design Studies, 62, 1-35. https://doi.org/10.1016/j.destud.2019.02.001.

McMichael, P. (1990). Incorporating comparison within a world-historical perspective: An alternative comparative method. American Sociological Review, 55(3), 385-397.

Mejlhede, D. T. (2015). Design research and art-based design education programs. Design Issues, 31(4), 44-55. https://doi.org/10.1162/DESI_a_00350.

NASAD. (2019). NASAD handbook. Resource document. National Association of Schools of Art and Design. https://nasad.arts-accredit.org/wp-content/uploads/sites/3/2018/12/AD-2018-19-Handb ook-FINAL-12-17-2018.pdf. Retrieved March 5, 2019.

Niche. (2019). 2019 best colleges with industrial and product design degrees in America. https://www. niche.com/colleges/search/best-colleges-with-industrial-and-product-design/. Retrieved February $23,2019$.

Norman, D. (2010). Why design education must change. Core 77. Nov 26. https://www.core77.com/ posts/17993/why-design-education-must-change-17993. Retrieved October 20, 2019.

Robert, W. (2006). At Media Lab, less whiz, more bang: High-flying MIT unit refocuses on the practical. Boston Globe. http://archive.boston.com/news/education/higher/articles/2006/08/12/at_media _lab_less_whiz_more_bang/. Retrieved March 5, 2019.

Self, J. A., Evans, M., Jun, T., \& Southee, D. (2018). Interdisciplinary: Challenges and opportunities for design education. International Journal of Technology and Design Education, 29(4), 843-876. https://doi.org/10.1007/s10798-018-9460-5.

Stake, R. E. (2005). Qualitative Case Studies. In N. K. Denzin \& Y. S. Lincoln (Eds.), The Sage handbook of qualitative research (pp. 443-466). Thousand Oaks: Sage Publications Ltd.

Tenorio-Trillo, M. (1996). Mexico at the world's fairs: Crafting a modern nation (Vol. 35). Berkeley: University of California Press. 
Thoring, K., Desmet, P., \& Badke-Schaub, P. (2018). Creative environments for design education and practice: A typology of creative spaces. Design Studies, 56, 54-83. https://doi.org/10.1016/j.destu d.2018.02.001.

Tong, H.-M. (2008). Expansion \& deteriorate: The contemporary crisis of design education in China. Art \& Design, 180(4), 56-63. (in Chinese).

Visser, W. (2009). Design: One, but in different forms. Design Studies, 30(3), 187-223. https://doi. org/10.1016/j.destud.2008.11.004.

Wang, M.-Z. (1985). Professor Lehmann's design basic teaching. Art \& Design, 13(3), 34-35. (in Chinese).

Yin, R. K., \& Heald, K. A. (1975). Using the case survey method to analyze policy studies. Administrative Science Quarterly, 20(3), 371-381.

Yuan, X.-F., \& Zhang, M. (2018). Constructing an informative design of China: An interview with Professor Yin Dingbang of Guangzhou Academy of Fine Arts. Design Research, 46(04), 1-5. (in Chinese).

Zhang, W.-W. (2013). American industrial design education. Packaging World, 147(02), 67-68. (in Chinese).

Zhang, L., \& Dou, J.-H. (2010). Re-analysis on the Industrial Design education of Chinese. In Innovation design and management: Proceedings of international innovation design and management summit forum in 2010 \& design academic conference of Chinese worldwide (pp. 382-384).Beijing: China Light Industry Press (in Chinese).

Publisher's Note Springer Nature remains neutral with regard to jurisdictional claims in published maps and institutional affiliations.

\section{Affiliations}

\section{Xuefei Huang $^{1}$ (D) $\cdot$ Roger Ball $^{2} \cdot$ Wei Wang $^{2}$}

Roger Ball

roger.ball@design.gatech.edu

Wei Wang

wei.wang@design.gatech.edu

1 School of Art and Design, Wuhan University of Technology, 122 Luoshi Rd, Wuhan, People's Republic of China

2 School of Industrial Design, Georgia Institute of Technology, 254 Fourth Street, NW, Atlanta, GA, USA 